\title{
A usability framework for speech recognition technologies in clinical handover: a pre- implementation study
}

Linda Dawson,

University of Wollongong, NSW, Australia.

Maree Johnson,

Centre for Applied Nursing Research (a joint facility of the South Western Sydney Local Health District and the University of Western Sydney), Sydney Australia.

Hanna Suominen

NICTA, The Australian National University, and University of Canberra Canberra, ACT, Australia

Jim Basilakis,

University of Western Sydney, Sydney, NSW, Australia

Paula Sanchez,

Centre for Applied Nursing Research, Sydney Australia.

Dominique Estival,

Centre for Applied Nursing Research, Sydney Australia.

Barbara Kelly,

The University of Melbourne, Melbourne, VIC, Australia

Leif Hanlen,

NICTA, The Australian National University, and University of Canberra Canberra, ACT, Australia

Corresponding author: Associate Professor Linda Dawson,

Corresponding Author's Contact Details:

Faculty of Social Sciences

University of Wollongong, NSW, Australia

Phone: +61242213821

Fax: +61 242214657

email: lindad@uow.edu.au 


\section{Abstract}

A multi-disciplinary research team is undertaking a trial of speech-to-text (STT) technology for clinical handover management. Speech-to-text technologies allow for the capture of handover data from voice recordings using speech recognition software and systems. The text documents created from this system can be used together with traditional handover notes and checklists to enhance the depth and breadth of data available for clinical decision-making at the point of care and so improve patient care and reduce medical errors. This paper reports on a preliminary study of perceived usability of nurses of the use of speech-to-text technology based on interviews at a "test day" and using a user-task-technology usability framework to explore expectations of nurses of the use of speech-to-text (STT) technology for clinical handover. The results of this study will be used to design field studies to test the use of speech-to-text (STT) technologies at the point of care in several hospital settings.

Keywords: usability; clinical handover; speech recognition; nursing; action research 


\title{
Introduction
}

\author{
Context of the study
}

The study presented in this paper is part of a larger study where a multi-disciplinary research team, comprising nurses, nurse educators, IT specialists and social linguists, is undertaking a trial of speech-totext (STT) technology for clinical handover management. This preliminary study aims to identify expectations of new users of speech-to-text technologies for clinical handover including expected benefits, costs, advantages, disadvantages and changes in work practices. Speech-to-text technologies allow for the capture of handover data from voice recordings using speech recognition software and systems. The text documents created from this system can be used together with traditional handover notes and checklists to enhance the depth and breadth of data available for clinical decision-making at the point of care and so improve patient care and reduce medical errors. The objectives of this smaller study are to explore speech-to-text hardware and software with nurses who are experienced with traditional clinical handover procedures. Other publications [1] report on the technical perspectives such as hardware and voice quality, software, algorithms and machine learning, word accuracy, etc.

\section{Clinical Handover}

Verbal and/or written clinical handover is one of the most common tasks carried out by nurses and relies on accurate clinical communication [2]. Failures in clinical communication can lead to adverse health events [3-5]. Although there are there are some very good systems in common use, such as the ISBAR system $[6,7]$, there is no universally accepted method of handover, most clinicians use a combination of verbal and written approaches [8-10]. It has also been found that communication errors can compromise patient safety in health care facilities $[2,11]$. A recent study identified $22 \%$ of clinical management incidents in nursing were caused by communication failures either at handover or within documentation resulting in delays to diagnosis and treatment [12].

\section{Digital Tools}

Jefferies, Johnson and Nicholls [13] compared the patient information delivered by nurses using oral clinical handover and using written nursing notes. They found that clinical handover presented a more complete picture of the patient's condition and care than the nursing notes which tended to focus on descriptions of nursing tasks. They suggest that new handover practices which encompass all patient information need to be explored including new technologies, systems and work practices. Clarke and Persaud [14] propose a model for clinical handover improvement which includes end user involvement and implementing locally adapted best practices supported by communication, documentation, and training.

Various electronic and digital tools have been proposed to assist in improving clinical decision-making at the point of care $[11,15-17]$ including the handover process, to decrease errors arising from inadequacies in the handover practice $[3,5,17,18]$. Others have investigated transforming work practices of nurses in the context of introducing new technologies in ward units as complex environments [19] using Complexity Theory [20] and Actor-Network Theory [21]. In this study [19], nurses rarely documented care at the patient bedside but sometimes wrote notes on a piece of paper, but the actual formal documentation was performed later in the operations centre. This formal documentation also provided an important means for information exchange between nurses, physicians, and ward secretaries. Thus they are an example of black boxing when existing technology and routines are intertwined in a way that is likely to be difficult to change. However, the study sees several opportunities for new technologies to make the unit less dependent on time-place arrangements and support in coordination, communication, and information sharing.

Existing technologies which can provide the digitisation and secure recording of handover information, especially speech-to-text technologies, provide the opportunity for the more comprehensive description delivered at handover by nurses to combine with nursing notes. This study is part of a project which seeks to enrich the collection and analysis of handover data by developing a Speech-To-Text for Clinical 
Handover System based on speech recognition of oral handover information and a customised database providing congruence between oral handover and nursing documentation so that all patient information can be accessed and analysed for clinical decision-making.

\section{The technology of speech recognition and translation}

It has been shown that speech recognition achieves up to 79 per cent of the words being correctly detected without any tailoring to a given voice on six realistic handover scenarios with over 1,200 words of continuous free-form text across the specialties of aged care, dementia, medicine, and neurology, and three Australian voices [1]. The voices included two native Australian-English speakers (male physician and female nurse) and one female nurse with a Spanish accent. The best word detection rate was achieved with the male voice and the worst $(53 \%)$ with the Spanish accented voice. The effects of background noise, interruptions, or other characterising that complicate speech recognition in clinical settings has been studied with eight voices and a total of about 3,600 typical short anaesthesia comments in Danish [22]. The detection recognition rate with free text was over 77 per cent in these noisy settings. Using from 30 to 60 minutes tailoring to a given voice shows detection recognition rates from 90 per cent to 99 per cent on four medical report entries (two progress notes, one assessment summary, and one discharge summary) and twelve US-English male physicians [23] 47 emergency-department charts and two USEnglish physicians [24], and 206 pathology reports from surgical pathology materials in seven CanadianEnglish pathologists and a primary evaluator who speaks English as a second language [25].

Information extraction to transform free-form text in the clinical domain has been studied on many formfilling applications. The review of the research published after 1995 by Meystre et al [26] discusses 174 publications on extracting information from free-form text in the electronic health/patient record. The review and references therein describes that systems developed to extract information from these texts mostly focus on chest and other types of radiography reports, echocardiogram reports, discharge summaries, and pathology reports. The typical tasks include extracting codes; enriching or structuring the content and utility of the electronic health/patient record, especially to support computerised decisionmaking; surveillance; supporting research; de-identification of clinical text; and terminology management. The conclusion is that from 1995 to 2008, the quality of these information extraction systems has gradually improved, exceeding the F-measure of 90 per cent in several cases. This F-measure is defined as the harmonic mean of precision (the proportion of extracted items that the system got right) and recall (the proportion of items that the system should have extracted and did extract). It takes values between zero (the worst quality) and 100 per cent (the best quality). As an example of a recent study on health information extraction, we refer the reader to $\mathrm{Xu}$ et al. [27]. They describe a system to extract medication dosage information from US discharge summaries that achieves the F-measure of 85 per cent after using 349 summaries with altogether labelled 27,837 text snippets to build the system.

\section{Research Approach}

As stated above, the research reported in this paper is a preliminary study which is part of a larger action research project investigating the implementation of speech-to-text in clinical handover in hospital wards. The research questions addressed in this study were:

- What are the expectations of participants who are about to commence using speech-to-text technologies for clinical handover?

- What advantages and disadvantages do participants expect when working with speech-to-text technologies for clinical handover?

The research approach for the preliminary study reported in this paper is empirical and interpretive and based on qualitative data transcribed from interviews with nurses who were introduced to the concepts of speech-to-text handover and the potential equipment to be trialled.

In this paper the focus is on evaluations by the participants of the usability of the hardware and software systems which could be used to collect voice-based clinical handover data, based on their own professional experience and their perceptions of how speech-to-text handovers may be carried out. Data was analysed within a usability framework based on accepted usability principles [28, 29] for the adoption of emerging technology in the workplace 


\section{The Framework}

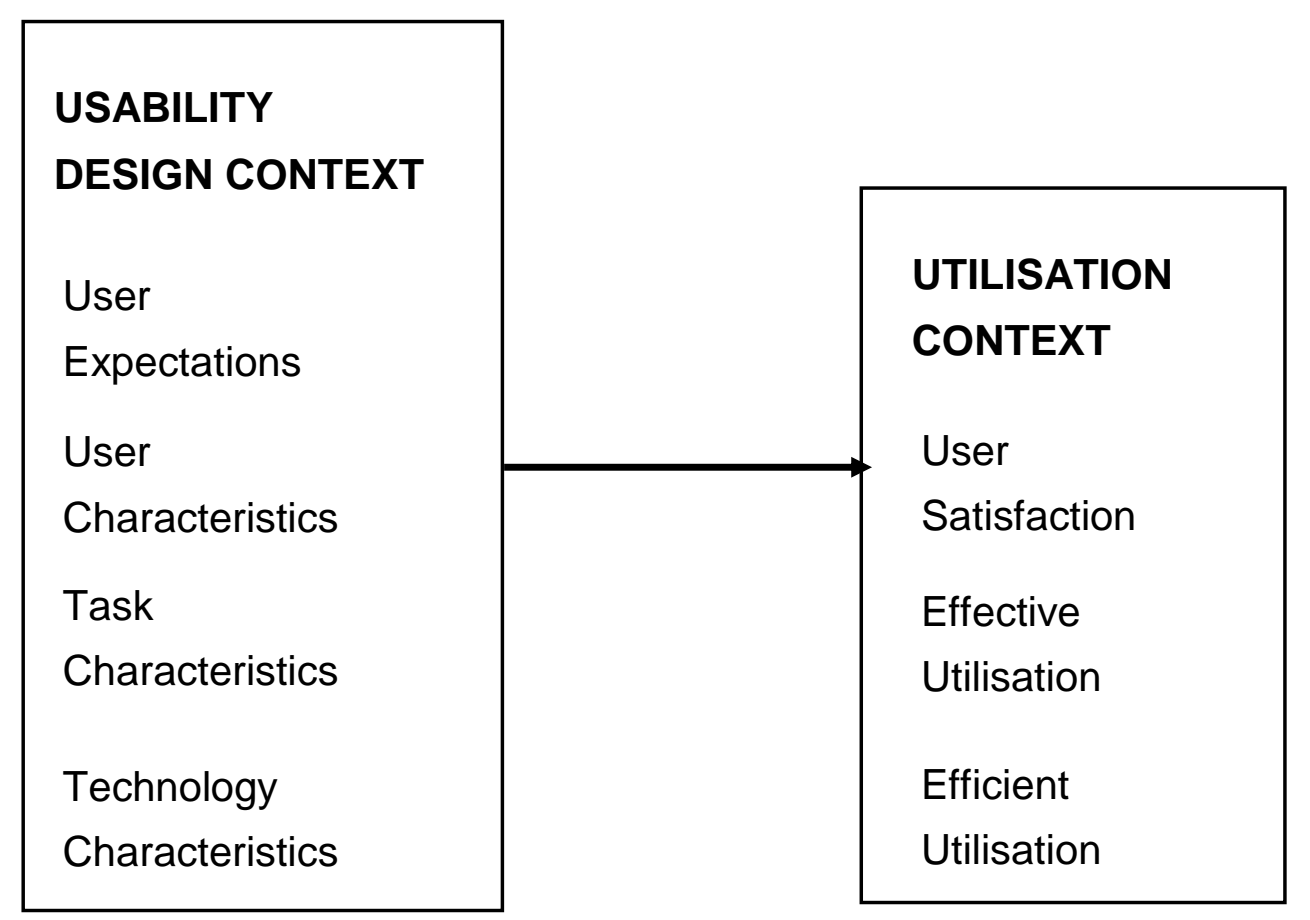

Figure 1: A Framework for user-task-technology usability (UTTU)

As a theoretical foundation for this study a framework for user-task-technology usability is proposed in Figure 1. Usability is generally defined as the effectiveness, efficiency and satisfaction with which specific users achieve specific goals within a particular context or environment [28, 30]. Nielsen [29] further emphasises the importance of the predesign stage in usability engineering which he describes as "Know the user" which includes understanding individual user characteristics, the user's current task, functional analysis and the evolution of the user. Another framework, the task-technology fit (TTF) framework acknowledges the importance of precursors of utilisation such as user expectations, attitudes and beliefs [31, 32].

Studies of usability have found that involvement of users in preliminary design assists in successful design. Venturi et al [33] found that successful User Centred Design relies on early involvement of practitioners in the product life cycle. Linholt et al [34] studied usability in the development of electronic health record (EHR) systems and suggest that "[a] way to involve the clinicians in the development process is conducting usability evaluations." and showed that it is possible to identify usability problems in an EHR system by combining methods from laboratory tests and field studies.

Context is a highly critical factor in understanding change and development needs for new systems [35, 36]. Recently, Coursaris and Kim [37] have suggested a Framework for Contextual Usability for mobile technology based on the following variables: user, task, environment, and technology, which focuses on users, tasks and technology in a specified context.

In this paper a framework for user-technology-task usability (UTTU) is proposed (Figure 1) based on the usability framework elements in Table 1 listed with supporting literature and specific descriptions relating to this project. 
Table 1: Framework elements and supporting literature

\begin{tabular}{|c|c|c|}
\hline Framework element & Supporting Literature & Speech-to-text project \\
\hline User expectations & $\begin{array}{l}\text { Liholt et al, Venturi, Nielsen, } \\
\text { Goodhue \& Thompson }\end{array}$ & $\begin{array}{l}\text { Expectations and attitudes to the } \\
\text { concept of STT handover }\end{array}$ \\
\hline User Characteristics & Nielsen, Coursaris \& Kim & $\begin{array}{l}\text { Experienced practicing } \\
\text { nurse/clinician }\end{array}$ \\
\hline Task Characteristics & Goodhue \& Thompson & $\begin{array}{l}\text { Mobile speech recording of clinical } \\
\text { handover notes }\end{array}$ \\
\hline Technology Characteristics & Coursaris \& Kim & Mobile, portable, recording devices \\
\hline Context & $\begin{array}{l}\text { Coursaris \& Kim, ISO-9241, } \\
\text { Pettigrew }\end{array}$ & $\begin{array}{l}\text { Recording environment } \\
\text { Translation process }\end{array}$ \\
\hline
\end{tabular}

The empirical research reported in this paper addresses the first part of the framework (left section of Figure 1 - Usability Design Context) which focuses on the "precursors" to design of a usable system by exploring potential users' expectations of the technology environment within their own framework of experience, beliefs and opinions.

A testing day was arranged with 5 practising clinicians where they were introduced to the concept of STT for clinical handover and various potential recording devices and systems. The participants were interviewed about their expectations of STT within a typical handover context based on their evaluation of the technologies and their own experience of clinical handover and understanding of the new STT for clinical handover environment.

\section{Findings}

The analysis of interview data was based on standard coding using the HyperResearch qualitative analysis tool [38] and the seed categories from the framework - user expectations, user characteristics, task characteristics, technology characteristics and environment. The analysis is presented below based on emerging themes from the coded data within the seed categories from the framework. Themes are further illustrated with selected quotes from the transcripts.

\section{User expectations - nurses}

\section{General expectations}

From an expectations perspective, the participants were generally very positive about the technology and anticipated potential improvements.

All five clinicians interviewed were willing to try STT technology if it were available, although there were some reservations,

"I just think it's a very, very good project. I'm very impressed by the fact that people are trying to look at the best interests of the patients, I mean that to me is the ultimate ... [j] ust having had ... the clinical communication workshops where I know that communication of handover is where students seem to be falling down." 
"I'm really excited. I'd hope it all works out and I can see it [being] implemented during my career because I'm only just starting and there are so many possibilities of what could be done with technology these days ..."

"Yeah, I think that would be great as long as all the bumps get smoothed out eventually but I'm sure that it will be difficult at the beginning ..."

All participants anticipated improvements to the handover process: "I think it's an absolutely fantastic idea because you can still ... reiterate [replay] if you didn't quite understand or even hear something ... this is a fantastic move towards the, not mechanising, ... but certainly making the handover more fluent..."

"... it's better because if you're writing you need to think everything in grammar, explain things ... . This is a better record and step by step."

"II]f it gave additional information and it improved patient safety, any option which improved patient safety, would be something that I'd adopt."

"So - but this is way far off and could make a whole different study - having a power chart of each person's information in the phone itself so that you could just swipe and get the medication. If you're carrying it in your pocket you don't have to go back to the desk to look at what the medication is or what the blood levels are or...everything, it could all be in your hand and your pocket constantly."

\section{Learning \& training}

All nurses were concerned about how they were going to prepare for a new system particularly whether there would be sufficient training: "... being au fait with the equipment, knowing how to use it. If it was extremely difficult to use and wasn't intuitive to be able to use, I'd probably become frustrated. I'd sort of think, we'll what's the point of trying to use equipment that most of us don 't understand how to use? "

Some participants thought that it would be problematic at first and then get easier similar to other IT systems: "... exactly the same as when you put the computer on, because everything you are writing on paper, after you go in the computer - it's a worry because it is a new system. But after, it's fantastic."

It was also suggested that it would take time for nurses to get used to new systems and that training would be vital: "But when it goes into service I think everything will be fine then, once they've had some education in it ... [t] hey know that they can't get away with not using it because ... [a] nurse unit manager will ... put this in place and say to the staff, well, I'm sorry, but we have to do it this way now. ... [s]o they won't have a choice."

One nurse suggested the need to train users on how to record data in the most accurate ways: "I think you have to learn [how to record accurate data] as well as the software."

\section{Time available}

Since nursing is naturally a time consuming job, there were concerns about whether sufficient time would be available to record and take or revise notes: "You know, would we have sufficient time to be able to record all of this because on a busy ward do you have that sort of time? I mean you do have to ... make your notes, so you'd have to set aside time to be able to make those notes anyway ... "

"... it's been my experience that you're actually inclined to say a little bit more and elaborate a little bit more than perhaps you might if you were just writing something down."

The suggestion by the facilitators that the voice recording may be translated into a rough draft that was editable created some concern: "... usually you handover the keys to the one in the charge and part your ways, wash your hands, then off you go. But they're really going to have to do something about handover times if they're going to incorporate this because then the person will have to come back after the handover, then sit down at the computer and actually, if they're going to revise notes, they'll - there will be blue murder some of them will scream ... as far as if editing takes them, say, 20 minutes and it's already five minutes to knock off time." 
There was concern over the time it might take to check and edit notes at night to morning handover. "... if editing takes them, say, 20 minutes and it's already five minutes to knock off time. It might take them over what they're supposed to be there. (Facilitator: So the procedures would have to change or the way they do - the relationship between it would have to be altered?) ... It depends on the type of ward it is I guess. It'd just be that - afternoon shift it really isn't a problem because you have such a large overlap between shifts. You can sit down and do your editing of your notes. But the one I see a problem with is the morning - night to morning shift."

\section{User characteristics - nurses}

Age

Three of the five nurses thought technology such as this is more suitable for younger people: 'T guess anyone who is maybe in their 20s and younger - 30s is still good-but once they start getting above their 30 s, I just think they don't maybe use computers as much or as often as the younger generation who are addicted to technology. So I would say they [an older generation] seem to complain a little bit more whenever they have to use a computer or ask for advice ..."

Some participants were concerned that some mature nurses are set in their ways: "There will be staff who will out-and-out refuse to use them. You'll get the cranky old nurses that have been there for a long, long time. I can just see many of my peers - years of education in emergency - T'm not using that stupid thing. I've given my handover like this for years."

"[J] ust about every person under 30 I see nowadays have [sic] got a telephone on them, ... especially one of these smart-phones... So I'm not too worried about the younger ones ... picking up the technology."

\section{Resistance}

Three of the five participants specifically identified resistance to technology and specifically resistance to being recorded: "Nurses don't like change. They'll put up resistance to something new that comes along. But usually once they start using it, especially technology that improves patient care, ... they'd see the value of it."

"It's additional to the [current] technology, ... Some people didn't like more technology to come to the field ... ten years ago ... I never used a computer ... It's all paperwork. Now everything, there's computer for ordering, ... all documentation it's all through the computer ... That's the issue. It's a new thing and it's a new technology coming to the handover, ... Some of them maybe they will not like it."

"They're scared. Everyone is frightened of a new system but after, it's fine ... for the computer everyone was scared. I was nervous because I [had] never used a computer, ... but after everyone's happy."

"You can think about maybe some nurses or some people, they don't like to be recorded. They don't like to be recorded and maybe they never ... record their voice. 'Why do you want me to record my voice? I can write.' Maybe they're happy to write, but they're not happy to be recorded. Maybe that interferes with their rights, they think."

\section{Task characteristics - clinical handover}

\section{Accountability, documented evidence and benefit to the patient}

Speech to text technology was generally seen as potentially making a positive contribution to the task of clinical handover. Specific contributions identified by the participants included providing documented evidence for enhancing accountability and clinical reasoning and associated benefit to the patient:

"I think that it's a very positive move in that it actually holds nurses a lot more accountable for what they say in handovers. Now, I know that might sound strange but, given probably thousands and thousands of handovers, quite often people will be quite blasé and not give much information. You've got to pull it out of them ..." 
"I think recording the handover would be easy for later on to have evidence for what you said, ... because handover is part of your nursing, takes sometimes half an hour, 45 minutes. You need to have them recorded. You document everything the whole day and this is one of the most important parts of your duties as a nurse ... at work."

"... I think that that's the advantage of [STT] handover is that although you write something in your notes, [using voice recording] you're more inclined to elaborate and say, you know the patient's really quite uncomfortable and they're really quite distressed, can you just make sure that they get additional TLC? or phone the family or something like that, which you might not necessarily write in your notes. So I think it might be an expansion on what you might be saying in your notes so I think it might be - yes perhaps a little bit more global and a bit more holistic."

One nurse liked the idea of a permanent record of handover. "Evidence [of] what you have, what you did, what you did during the day, what you hand over to the next shift ... It's like nursing documentation, I think. It's the same value of nursing documentation."

"... this is a fantastic move towards the, not mechanising, you know what I mean, but certainly making the handover more fluent and, as I said, about accountability. To be able to recount notes as well rather than say, oh, what did Sally say this morning when she handed over about such and such."

"... to refresh your memory but also if you picture being, say - ... the night duty nurse [was] really worried about this patient. So in the morning [the patient is] handed over to me. Now, look at this lady. ... I'm not too sure what's going on with her. She looked to me like she was going to have a seizure last night. She raised her blood pressure. She went all dazed as if she was having an absent seizure or something. She didn't have any involuntary movement or anything. But I was just worried about her.' Now, if I totally ignored that in the handover and said, oh, look, she looks all right now, she's eaten a bit of breakfast, and didn't do a damn thing - now that person maybe had a seizure and then died later or hit her head or something happened that was really, really nasty. Then they say, well, she didn't tell us anything about it. So there is that accountability that you've got proof saying, hang on, I did hand that over this morning."

Other practical improvements identified by participants in interviews included in-situ data collection, backup of handover data, playback between shifts, time-savings, continuity of care and an aide de memoir. Some negative contributions of STT to the task of clinical handover identified by the participants included the effect on relatives of recording in their presence and infection control.

\section{Technology Characteristics - mobile, portable speech recording}

Before the interviews, all clinicians were shown how to use various mobile recording devices including a smartphone, a tablet, an MP3 player and a standard Dictaphone. Practical issues identified with all devices included: maintenance (battery life), cost of the device, potential damage to the device, responsibility for the device and its data, ease of use (headsets, lapel microphones).

The most popular devices were the smartphone and the tablet, and noise cancelling lapel microphones were preferred by most clinicians over headsets:

"I think it would have to probably be the smartphone because it would be so much easier to transport and walk around with ...".

"Oh the tablet, straight away it was just so much more intuitive, so much more user-friendly. You just pressed one button and it worked and it was - you know you didn't have go back to menus .... So the tablet would be my first preference. I'd probably then say the next one would be the smartphone, although I'd have to be fairly au fait with how it worked."

"It would definitely be the smart phone, especially since it has the potential to maybe integrate other features eventually, so you could use that all the time. ..."

"The [smartphone]. ... Most of the people can navigate [a smartphone], especially you're talking about the new generations and ... the little MP3 player's probably a bit too basic and probably too unreliable. ... A bit of a toy. ... I think the voice recorder would be excellent quality. But it might be a little bit more complicated for those who are the less techno savvy as far as your menuing (sic) system ... I think it's very basic too - if you just look at the markings and things. The smartphone that was so easy to operate, as is 
the tablet. I mean, it's just more or less a couple of touches and you're off and, of course, to stop and save."

"I mean most of the devices are pretty portable already and that's why I suggested not the [tablet] because you can't really put [a tablet] in your pocket."

"Yes. It's [the tablet] better I think because every single day you put it straight away into the computer, ... it's connected. It's the easiest. ... you check the record of the resident. It is still there to compare what happened from yesterday and manage reports."

"I enjoyed the lapel microphones better but if one of the devices, the final device, could not have any headphones at all, if you could just talk at it instead of having to put something in your ears or around your neck, like the [smart]phone and the [tablet], it just hears your voice, you don't need to connect anything. And the voice recorder as well, whereas the MP3 I'm pretty sure you need a headphone and a microphone to make it work. So the less things you have, the less clutter, the less things getting lost. It would be more efficient to not have microphones."

\section{Environment Characteristics: Context of clinical handover using speech recognition technology}

\section{The Recording Process}

Various physical issues with the recording process were identified by interviewees including ambient noise, and tacit recording of both patients and staff which may breach patient confidentiality.

"Especially emergency departments or things like that where you've got a lot of - hopefully not too much yelling and screaming but it does happen, and of course just the ambient noise in the place anywhere. It's all the clattering, banging and it's just a very noisy place. ... You'd have to have something that could filter out the really loud bangs or the high-end clicks and clangs and things ..."

"So as long as I was reassured that there was patient confidentiality and that the device that I was using was intuitive and user-friendly, I think it would be a very good tool to be able to use. If not I'd be - you know, probably might have a bit of a negative attitude towards it."

"So if they were walking around in their normal social environment I think you'd have to be very careful how you managed it then. Because, indeed - you know just from the confidentiality perspective - if you're actually recording and there might be patients and patients' relatives around and that sort of thing, I think that could potentially be a breach of confidentiality and I'm not sure how you would get around that."

\section{The Translation Process}

Nurses were also concerned about the transcription process in terms of how accurate it would be and the handling of accents, slang, abbreviations and recording people with English as a second language.

"I'm assuming it's probably going to be difficult for the technology itself to recognise the different speech patterns and maybe accents and just in general I've noticed even with the caption on TV that does it automatically that it doesn't always pick up the correct words. YouTube's text program is pretty bad as well; it doesn't pick it up properly. So I guess that it generally needs to be advanced a little to make it work efficiently, especially if we're doing it in a medical field, like if it picks up something wrong and then it gets translated incorrectly, it could make even more errors."

"... maybe we've got to look at slang, we've got to look at abbreviations and all those sorts of things as well and how do you change that? I don't know because I certainly know that students that have English as a second language really struggle with that. They really - I mean the Aussie vernacular is very interesting isn't it? So whether you improve on that and you try to get rid of some of the slang and some of the abbreviations, that might be a way forward as well because there's a lot of misunderstanding about that." 
"I don't know. For the other staff, different accents, for example. For example, I say Mr 'Flemington', for example, another nurse says 'Flemington' - different pronunciation, different surname. It would be the same in writing but different pronunciation, properly, exactly."

\section{Discussion}

The purpose of this study was to identify preliminary issues which may influence successful utilisation of STT technology in clinical handover trials by asking practising nurses to evaluate some of the elements of a STT environment before implementation. The evaluations by the nurses will assist in the selection of the hardware and software together with the design of processes and procedures to be used in field trials of the larger study at eight wards within two hospitals in NSW, Australia.

\section{Speech recognition and translation}

The accuracy of the recording and translation process was discussed by some of the participants and the level of difficulties identified was surprising. The participants perceive much lower levels of accuracy may be acceptable. As discussed above, many studies in speech recognition and information extraction with health data [1,22-25] show that our participants concerns with inabilities of technologies to cope with the technical aspects of speech recognition and translation in real-life setting are likely to be unfounded. This will need to be investigated by field trials. The combined use of existing systems with speech-to-text technology may minimise the translation issues identified in the discussion such as accents, speech patterns and pronunciation. Further, if team members know what is being handed over in what order the usability may be enhanced.

\section{Preferred hardware - portability, less clutter}

The nurses interviewed in this study preferred hardware that was portable, with systems that were easy to learn, easy to navigate and as intuitive as possible. So, the most preferred hardware were the smartphone and the tablet although the tablet was seen as easier to use but not very portable in a hospital ward. The smartphone was seen as portable but not as easy to use and navigate as the tablet. This may be because the tablet is closer to a desktop or laptop computer in interface design than the smartphone. These differences may also be due to different generations of users (as pointed out by several participants) where smart-phones a just a part of life to younger generations whereas older generations may be more comfortable with a more traditional PC interface. Portable hardware, microphone or no microphone, and file systems were seen as complicated on the Dictaphone and MP3 devices.

\section{Changing work practices - training, support and ward champions}

Successful implementation of new technologies and overcoming resistance requires training, support and champions [39-41]. A training team needs to be established. The nurses interviewed in this study identified specific issues around the hardware system environment including understanding devicespecific menu and navigation systems and knowing how to make "good" and accurate recordings which are as good as or better than traditional written notes. The issues raised around age and previous experience with technology also need to be addressed in training and implementation.

Therefore, a support team including champions of the system and the technology will be necessary (probably drawn from the training team) to facilitate the take up on the ward of the new system. This would provide on the job assistance with the process in terms of file management and clarity about how to create text versions of voice recordings, who would edit text versions, where and when this editing would take place, etc. all necessary in the implementation phase. The maintenance of recording devices including supply of batteries, security, backup of files, and initialisation for start of shift identified as issues by participants also need to be addressed in a STT for clinical handover context.

\section{Conclusion}

This study, based on exploring user-task-technology usability issues with experienced clinicians as precursors to successful utilisation of STT for clinical handover, has provided valuable design context information for developing field trials of the technology for further research into improving clinical 
handover. This field research will provide empirical data relating to the Utilisation Context (right section of Figure 1 - Utilisation Context).

The results of this study indicate that to create a successful utilisation context in terms of usertechnology-task usability for speech to text technology in a hospital ward setting, portable hardware with interface systems that are easy to learn, easy to navigate and as intuitive as possible are necessary. Further, these technological environments cannot be successfully utilised without sufficient training and support particularly from in-house champions and systems and procedures to support new work practices.

Ultimately, improving and enriching the information provided at clinical handover by extending paperbased notes with voice-based notes collected using speech recognition technologies has the potential to reduce the number of Adverse Health Events (AHEs) due to incomplete communication at clinical handover. Also, notes collected using speech recognition technologies can be integrated with electronic patient records [10, 13, 42-44] and so provide potential for improvements in care planning, maintaining clinical histories, and more detailed information for other clinical decisions both at the point of care and within the patient journey.

\section{References}

1. Suominen H, Basilakis J, Johnson M, Sanchez P, Dawson L, Hanlen L, Kelly B. Preliminary Evaluation of Speech Recognition for Capturing Patient Information at Nursing Shift Changes: Accuracy in Speech to Text and User Preferences for Recorders. In: Suominen H, editor. Louhi 2013, Fourth International Workshop on Health Document Text Mining and Information Analysis; Sydney, NSW, Australia 2013.

2. Johnson M, Cowin LS. Nurses discuss bedside handover and using written handover sheets. J Nurs Manag 2013 Jan;21(1):121-9.

3. Farhan M, Brown R, Woloshynowych M, Vincent C. The ABC of handover: a qualitative study to develop a new tool for handover in the emergency department. Emerg Med J 2012 Dec;29(12):941-6.

4. Bhabra G, Mackeith S, Monteiro P, Pothier DD. An experimental comparison of handover methods. Ann R Coll Surg Engl 2007 Apr;89(3):298-300.

5. Barnes SL, Campbell DA, Stockman KA, Wunderlink D. From theory to practice of electronic handover. Australian Health Review 2011;35(3):384-91.

6. Finnigan MA, Marshall SD, Flanagan BT. ISBAR for clear communication: one hospital's experience spreading the message. Australian health review : a publication of the Australian Hospital Association 2010 Nov;34(4):400-4.

7. Eggins S, Slade D. Clinical handover as an interactive event: informational and interactional communication strategies in effective shift-change handovers. Communication \& medicine 2012;9(3):215-27.

8. Holly C, Poletick EB. A systematic review on the transfer of information during nurse transitions in care. Journal of clinical nursing 2013 Jun 21.

9. Mardegan K, Heland M, Whitelock T, Millar R, Jones D. Developing a medical emergency team running sheet to improve clinical handoff and documentation. Joint Commission journal on quality and patient safety / Joint Commission Resources 2013 Dec;39(12):570-5.

10. Johnson M, Sanchez P, Suominen H, Basilakis J, Dawson L, Kelly B, Hanlen L. Comparing nursing handover and documentation: forming one set of patient information. Int Nurs Rev 2014 Mar;61(1):73-81.

11. Hanada E, Fujiki T, Nakakuni H, Sullivan CV. The effectiveness of the installation of a mobile voice communication system in a university hospital. Journal of medical systems. [Research Support, Non-U.S. Gov't]. 2006 Apr;30(2):101-6.

12. Tran DT, Johnson M. Classifying nursing errors in clinical management within an Australian hospital. Int Nurs Rev 2010 Dec;57(4):454-62.

13. Jefferies D, Johnson M, Nicholls D. Comparing written and oral approaches to clinical reporting in nursing. Contemporary Nurse. [Report]. 2012 2012/08//;42(1):129+.

14. Clarke CM, Persaud DD. Leading Clinical Handover Improvement: A Change Strategy to Implement Best Practices in the Acute Care Setting. Journal of Patient Safety 2011 Mar;7(1):11-8.

15. Marukami T, Tani S, Matsuda A, Takemoto K, Shindo A, Inada H. A basic study on application of voice recognition input to an electronic nursing record system -evaluation of the function as an input interface. Journal of medical systems. [Evaluation Studies]. 2012 Jun;36(3):1053-8. 
16. Unluturk MS. Advanced nurse-patient communication system. Journal of medical systems 2012 Aug;36(4):2529-36.

17. Martinez-Perez B, de la Torre-Diez I, Lopez-Coronado M, Sainz-de-Abajo B, Robles M, GarciaGomez JM. Mobile clinical decision support systems and applications: a literature and commercial review. Journal of medical systems 2014 Jan;38(1):4.

18. Celikkan U, Sahin YG, Senuzun F. Perceived usefulness of data entry tools in medical encounters: a survey. Journal of medical systems 2013 Dec;37(6):9988.

19. Vuokko R, Karsten H. Transforming work practices in a complex environment. Int Fed Info Proc 2008;267:143-57.

20. Anderson P. Complexity theory and organization science. Organ Sci 1999 May-Jun;10(3):216-32.

21. Latour B. Reassembling the Social. An Introduction to Actor-Network Theory. Oxford, UK: Oxford University Press; 2005.

22. Alapetite A. Impact of noise and other factors on speech recognition in anaesthesia. Int $\mathbf{J}$ Med Inform 2008 Jan;77(1):68-77.

23. Devine EG, Gaehde SA, Curtis AC. Comparative evaluation of three continuous speech recognition software packages in the generation of medical reports. J Am Med Inform Assn 2000 Sep-Oct;7(5):462-8.

24. Zick RG, Olsen J. Voice recognition software versus a traditional transcription service for physician charting in the ED. Am J Emerg Med 2001 Jul;19(4):295-8.

25. Al-Aynati MM, Chorneyko KA. Comparison of voice-automated transcription and human transcription in generating pathology reports (vol 127, pg 721, 2003). Arch Pathol Lab Med 2003 Oct;127(10):1348-.

26. Meystre SM, Savova GK, Kipper-Schuler KC, Hurdle JF. Extracting information from textual documents in the electronic health record: a review of recent research. Yearb Med Inform 2008:128-44.

27. Xu Y, Hong K, Tsujii J, Chang EIC. Feature engineering combined with machine learning and rule-based methods for structured information extraction from narrative clinical discharge summaries. J Am Med Inform Assn 2012 Sep;19(5):824-32.

28. ISO Standard 9241. Ergonomic Requirements for Office Work with Visual Display Terminals (VDTs) - Part II: Guidance on Usability: International Organization for Standardization; 1998.

29. Nielsen J. The Usability Engineering Life-Cycle. Computer 1992 Mar;25(3):12-22.

30. Jokela T, Siponen M, Hirasawa N, Earthy J. A survey of usability capability maturity models: implications for practice and research. Behav Inform Technol 2006 May-Jun;25(3):263-82.

31. Goodhue DL, Thompson RL. Task-Technology Fit and Individual-Performance. Mis Quart 1995 Jun;19(2):213-36.

32. McGill T, Klobas J. User developed application success: sources and effects of involvement. Behav Inform Technol 2008;27(5):407-22.

33. Venturi G, Troost J, Jokela T. People, organizations, and processes: An inquiry into the adoption of user-centered design in industry. Int J Hum-Comput Int 2006;21(2):219-38.

34. Lilholt LH, Pedersen SS, Madsen I, Nielsen PH, Boye N, Andersen SK, Nohr C. Development of Methods for Usability Evaluations of EHR Systems. St Heal T 2006;124:341-6.

35. Pettigrew AM. Longitudinal Field Research on Change: Theory and Practice. Organ Sci 1990 Aug;1(3):267-92.

36. Pettigrew AM. Context and Action in the Transformation of the Firm: A Reprise. J Manage Stud 2012 Nov;49(7):1304-28.

37. Coursaris C, Kim D. A Qualitative Review of Empirical Mobile Usability Studies. AMCIS 2006.

38. HyperResearch. HyperResearch: a software tool for quaitative data analysis. Researchware; 2012.

39. Dawson L, Fisher J, Heslop L. Investigating the potential improvement of patient management systems in hospital ward settings using mobile, wireless technologies. First European Conference on Mobile Government; 2005; Brighton, UK.

40. Dawson L, Fisher J, Weeding S, Heslop L, Howard A. Action Research in Emerging Technologies in Health Information Systems: Creating a Mobile Information Environment in a Hospital Ward. 8th European Conference on Research Methodology for Business and Management Studies 2009:127-35.

41. Fernando J, Dawson L. Clinician assessments of workplace security training-an informatics perspective. electronic Journal of Health Informatics 2008;3(1):e7.

42. Lamond D. The information content of the nurse change of shift report: a comparative study. Journal of advanced nursing 2000 Apr;31(4):794-804. 
43. Irving K, Treacy M, Scott A, Hyde A, Butler M, MacNeela P. Discursive practices in the documentation of patient assessments. Journal of advanced nursing 2006 Jan;53(2):151-9.

44. Liu W, Manias E, Gerdtz M. Medication communication between nurses and patients during nursing handovers on medical wards: a critical ethnographic study. International journal of nursing studies 2012 Aug;49(8):941-52. 


\section{University Library}

\section{- M M N E R VA A gateway to Melbourne's research publications}

Minerva Access is the Institutional Repository of The University of Melbourne

Author/s:

Dawson, L;Johnson, M;Suominen, H;Basilakis, J;Sanchez, P;Estival, D;Kelly, B;Hanlen, L

Title:

A usability framework for speech recognition technologies in clinical handover: A preimplementation study

Date:

2014-06-01

Citation:

Dawson, L., Johnson, M., Suominen, H., Basilakis, J., Sanchez, P., Estival, D., Kelly, B. \& Hanlen, L. (2014). A usability framework for speech recognition technologies in clinical handover: A pre-implementation study. JOURNAL OF MEDICAL SYSTEMS, 38 (6), https:// doi.org/10.1007/s10916-014-0056-7.

Persistent Link:

http://hdl.handle.net/11343/283283 